\title{
Sinonimia, variación y sintaxis concordante en el Poema de Fernán González
}

\author{
Raúl Arístides Pérez Aguilar* \\ Universidad de Quintana Roo \\ Academia Mexicana de la Lengua
}

\begin{abstract}
Resumen
Se analiza el uso de sinónimos y variantes en el Poema de Fernán González para determinarlo en sus contextos de acuerdo con los recursos literarios que el autor maneja y con la norma lingüística imperante en el español del siglo XIII. Ambos usos se estudian por parejas de voces mediante su cronología y frecuencia de aparición en el texto, así como la posición que ocupan en los versos para conformar la rima y/o el metro, y los significados que suelen tener en los contextos en que aparecen. Se alude a la presencia de la sintaxis no concordante en perífrasis verbales regidas por haber como forma de expresión del español naciente y como consecuencia de la utilización de los cánones de la cuaderna vía.
\end{abstract}

Palabras clave: sinónimo, variación, significado, español siglo XIII.

* Para correspondencia, dirigirse a: Raúl Arístides Pérez Aguilar (rauperez@uqroo.edu. mx), Universidad de Quintana Roo,Boulevard Bahía s/n esq. I. Comonfort, Col. Del Bosque, CP 77019, Chetumal, Quintana Roo, México. 


\title{
SYNONYMY, VARIATION AND CONCORDANT SYNTAX IN THE POEMA DE FERNÁN GONZÁLEZ
}

\begin{abstract}
The use of synonyms and variants are analyzed in the Poem of Fernán González from their contexts and according to the literary resources employed by the author and to the linguistic norm prevalent in the Spanish of the $13^{\text {th }}$ century. Both uses are examined with couples of voices through their chronology and frequency in the text, their position within the verses to maintain the rhyme and the metric, and their meanings in the contexts they usually occur. The presence of non-concordant syntax in verbal phrases governed by haber is claimed to be a way of expression of the new-born Spanish and as an outcome of the use of the canons of the verses with four alexandrines.
\end{abstract}

Keywords: synonyms, variants, meanings, spanish 13th century.

Recibido: 14/06/16 Aceptado: 30/07/17

\section{INTRODUCCIÓN}

El Poema de Fernán González cuenta parte de la vida de este conde castellano nacido hipotéticamente entre 890 y 895 , muerto en 970 y dueño de un poder guerrero y de persuasión que logró afianzar la conciencia política castellana gracias a sus victorias sobre los moros invasores durante las batallas de Reconquista española.

En un texto incompleto escrito hacia $1250^{1}$ en versos alejandrinos, con rima grave y aguda y cierta métrica irregular, el autor del poema, un castellano viejo, monje o familiar del monasterio burgalés de Arlanza (Menéndez Pidal 1975: 198) pretende hermanar la materia heroica y lírica de libros anteriore ${ }^{2}$ con la cuaderna vía de reciente adopción en una serie de hechos narrados que, si bien no tienen la fuerza épica y calidad literaria del

Menéndez Pidal lo sitúa hacia 1240, en tanto que Gómez de la Cortina y Hugalde, los traductores de Historia de la literatura española de F. Boutervek, dicen que es del siglo XIV (p. 154).

2 Se pueden citar obras como la Razón de amor, el Poema de Mío Cid, el Libro de Apolonio, el Libro de Alexandre que posiblemente fueron conocidas por este autor. Habría 
Poema del Mío Cid, es uno de los tantos documentos que se han utilizado para conocer el estadio de la lengua española en el siglo XIII.

A pesar de ser un texto literario en el que se puede apreciar un arduo trabajo de versificación ${ }^{3}$ y un conocimiento amplio aunque incompleto de la historia de Castilla, es decir, aunque se trate de un trabajo hecho por una persona culta, contiene elementos lingüísticos del hablante común que poblaba Castilla en esos tiempos, hablante que, con suerte, haya formado parte, alguna vez, del público que escuchó a don Armillo, el juglar de Burgos, hacia 1221, cantar las gestas de Fernán González y del Cid (Menéndez Pidal 1975: 197) en un ambiente parecido al que se recrea en la estrofa 427 del Libro de Apolonio cuando la noble Tarsiana hecha juglaresa toca la viola y canta un romance:

Començo unos viesos e unos sones tales que traien grand dulçore e eran naturales. Finchanse de omnes apriessa los portales non les cabie en las plaças, subiense a los poyales.

o que, quizás, escuchó fragmentos de este mismo libro compuesto posiblemente en Aragón o del Libro de Alexandre, escrito en el reino de León, poemas de clerecía que fueron materia insoslayable del espectáculo juglaresco que un juglar del siglo XV recuerda haber oído (Menéndez Pidal 1975: 197) ante un público callejero de ínfima clase ${ }^{4}$.

Esto conduce a pensar que este tipo de literatura-la llamada de clerecíaal estar no solamente destinada a la lectura en la soledad pues se deslizó hacia la boca de los juglares, según vimos, hubo de tener un léxico conocido, un léxico usual, cotidiano y un estilo menos cuidadoso en los detalles formales y más atento a los efectos de las historias narradas. En este caso, el Poema de Fernán González, al presentar 143 versos que no caben en el

que agregar la obra de Gonzalo de Berceo y tal vez la Chronicum Mundi de don Lucas de Tuy y la Historia Gothorum de San Isidoro.

Versificación que, a veces, pasó idéntica a la redacción de la Primera Crónica General en tiempos de Alfonso X. Compárense por ejemplo el verso 203a: "En muchas otras cosas se despyende el aver" con "...et ganar dellos treguas, ca en muchas cosas se despyende ell aver; et en tal fecho..." (p. 392).

4 La presencia del Libro de Apolonio y del Libro de Alexandre en el repertorio de los juglares lo atestigua Menéndez Pidal (1975: 197) al citar los versos que el trovador catalán Guerau de Cabrera dirige al juglar Cabra y le censura no conocer muchas historias de temas clásicos. Sin embargo, al asentar que esto ocurrió en 1170 en Cataluña, se descarta que se aluda a las versiones castellanas de estos libros pues éstas son posteriores. Seguramente, se trata de otras versiones en otra lengua que circulaban en Europa tempranamente. 
metro alejandrino (Marden 1904: lii) evidencia una irregularidad métrica que no aparece en Berceo, pero es muy cuidadoso de los efectos que pueda causar en el lector y en el público el uso de imágenes plásticas que revelen un valor humano universal:

El conde orgulloso, de coraçon loçano, oyredes lo que fizo al conde tolosano:

desguarneçiol' el cuerpo el mismo con su mano

nol' fyzo menos honrra que si fues su ermano. 373

El tema heroico del Poema de Fernán González lo aleja de las alcobas cortesanas en las que se leían vidas de santos, serventesios o baladas acompañándolos con laúdes, cítolas y zampoñas, y lo acerca más a los mercados, plazas y demás sitios públicos en los que se regodeaban los juglares y también a las comidas de los caballeros en las que, según las costumbres antiguas, se leían historias de grandes hechos de armas para templar el ánimo y el esfuerzo, y aún más en las que "los juglares non dixiesen ant'ellos otros cantares sinon de gesta o que fablasen de fecho d'armas" como asienta Alfonso El Sabio en las Partidas. Este ánimo del autor de ser escuchado por un público, él mismo lo expresa en fórmulas juglarescas:

Cantar vos he primero en commo la perdieron, $3 \mathrm{a}$

El conde don Yllan, bien avedes oydo, 42a

Este mismo ánimo le da al poema completo un lenguaje llano en el que se mezclan la historia y la leyenda en un solo soplo vivo de épica popular asentado con una retórica culta propia de la clerecía. Esto le da una fuerte individualidad al texto frente a otras composiciones análogas.

\section{PROPÓSITOS}

Nos ha de servir este poema como cala para estudiar algunas voces usuales en la Castilla del siglo XIII, palabras de gran vitalidad en aquella época que van a convivir -algunas- en una lucha constante con otras para tratar de imponer su significación y uso en todos los sectores sociales (los sinónimos), o bien batallarán diversas formas de una misma en la que solo una será la vencedora (como ocurrió en tiempo pretérito con jenair/enero) y muchas otras. La victoria, como siempre, la dará el hablante. En este sentido, nuestro propósito será analizar el uso de algunos vocablos en el poema y determinarlo 
en sus contextos de acuerdo con los recursos literarios que el autor maneja y con la norma lingüística imperante.

La hegemonía de la lengua castellana sobre los demás dialectos peninsulares no se dio sino hasta después del siglo XI (Menéndez Pidal 1979: 125) gracias a la reconquista de Toledo (1085) y al gran desarrollo de la literaura y cultura castellanas que, al extenderse hacia el sur, desalojó a los dialectos mozárabes y rompió el lazo de unión lingüística que existía entre los extremos occidental y oriental de la península. No obstante, se muestra como un dialecto que no tiene estabilidad en su sistema nombre sobre nomne no se propaga sino después del siglo XII, las formas comde y semdero tienen todavía claro uso en Burgos hacia 1240 y en Toledo hacia 1260 (Menéndez Pidal 1979: 123), en la lengua escrita del siglo XIII se pueden hallar formas como siarra y sierra, pourta, puerta en Toledo, León y Aragón, en tanto que en Burgos, ya desde el siglo X se usaba la variante eufónica ue (Menéndez Pidal 1979: 141). Por otro lado, lejos han quedado en Castilla el uso de palomba, conelyo 'conejo' de fonética mozárabe o muller 'mujer' aunque todavía no se asoma plenamente una norma lingüística que sitúe a las palabras en un uso generalizado producto de la costumbre de los hablantes en su comunicación cotidiana. Y el Poema de Fernán González es un buen repositorio de estas formas que aún no llegan a consolidar su vitalidad en la lengua de todos los días.

Sigo la edición del manuscrito escurialense del poema que maneja Zamora Vicente (1954) enriquecido con algunas observaciones de Menéndez Pidal, con las jugosas notas de este último y la puesta al pie de página de fragmentos de la Primera Crónica General que permiten, al seguir la lectura, comparar los datos.

\section{LOS MATERIALES}

\section{Sinonimia}

\section{Troçido/passado}

La forma troçido aparece solamente en dos versos del poema: commo ovo por las paryas a Marruecos troçido; $42 \mathrm{~b}$ por las puertas de Aspa fueron luego troçidos, 138b

En tanto que la forma passado está en muchos más:

Fue luego pora'l rrey qual ora era passado, 48a 
Es usado en otros seis versos con el mismo significado de 'moverse de un sitio a otro' en forma de verbo conjugado:

Despydios' de los moros, luego passo la mar, 47a

Sopo Bernald del Carpyo que frranceses passaban, 132a

quando fueron juntados passaron allend mar, $72 \mathrm{~b}$

En forma de infinitivo:

Todos muy byen guisados por a Spanna passar, 72a

$\mathrm{Y}$ en forma de perífrasis verbal:

fueron aquestas nuevas a Marruecos passadas, $71 \mathrm{~b}$

non podieron los moros por los puertos passar, $88 \mathrm{c}$

A pesar de que Zamora Vicente (1954: 12) nos refiere en una nota que troçir tiene un uso frecuentísimo por 'pasar' y anote citas del Poema de Mío Cid y de Los Milagros de Nuestra Señora de Berceo, vemos que es superado en número por passar en sus diversas formas, y si a las anteriores les agregamos la docena que aparecen aunque con los significados de 'morir' (un caso):

Quando los rreyes godos deste mundo passaron, 25a

de 'padecer' ( 8 casos):

gentes nunca passaron atan mal ventura, $179 \mathrm{~d}$

o de 'transcurrir' ( 3 casos):

quantos en valde passan nunca los cobrraremos, $354 \mathrm{c}$

la diferencia de uso se hace más ostensible.

Finalmente, atravessar sólo aparece en dos versos:

travessaras la mar con todo tu fonsado, $46 \mathrm{~b}$

Y trrespassare en uno con problemas de métrica:

Trrespassare mucho ayna la mar, $45 \mathrm{a}$

Vemos, por otro lado, que de las perífrasis verbales con passar que el poema ofrece (versos 48a, 71b, 88c) más la de travessar (360a) y las dos con troçido (42b y 138b), 5 de ellas tienen una estructura no adyacente, es decir, intercalan elementos entre el auxiliar y el infinitivo o participio, y cuya causa es la necesidad de iniciar y/o mantener la rima del tetrástrofo:

non pudieron los moros por las puertas passar, $88 \mathrm{c}$

e ovieron por tanto las Asturyuas fincar. 88d.

Quando fueron las armas desfechas e quemadas, 71a

fueron aquestas nuevas a Marruecos passadas, $71 \mathrm{~b}$ 
Quando ovo el buen conde el rrio atravessado, 360a

fferio luego en ellos commo venia yrado, 630b

Las dos apariciones de troçir son también formas perifrásticas no adyacentes y, posiblemente, no tan usuales en el habla común, pues son más propias de la lengua literaria que aún la conserva con una frecuencia escasa, como en este caso. Un hablante común castellano del siglo XIII no diría: por las puertas de Aspa fueron luego troçidos (138b), sino fueron troçidos luego por las puertas de $\mathrm{Aspa}^{5}$, rompiendo el hipérbaton y siguiendo la llaneza del habla coloquial, como puede apreciarse en la Primera Crónica General: ...porque te yo pueda sacar y servir Castiella (p. 390), ..., en la que, sin embargo, puede leerse: Despues que Hercules ovo tod esto fecho... (p. 8, aunque también puede leerse: Despues que esto ovo fecho... 25 renglones debajo en la misma página.

Las estructuras perifrásticas adyacentes más cercanas al uso del hablante común también las usa el poeta con regular frecuencia:

de las cosas pasadas que yo pueda contar, 2c

además de la otra forma no adyacente ya comentada que, en el ejemplo siguiente no tiene la misma causa de uso, es decir, conseguir la rima:

fueron por la verdat metidos a espada. 10d

ni obedece a cuestiones de métrica, pues aun juntando el auxiliar con el participio, el número de sílabas sigue siendo el mismo.

Creo se trata de una cuestión de estilo en que la obra de Berceo tiene mucho que ver con el uso de estas formas perifrásticas anómalas:

Fueron de Sancty Spirytus los godos espirados, 20a

Fueron de Sancto Spiritu una vez aspirados (Loores de Nuestra Señora, $129 \mathrm{c})$.

Vemos así 4 sinónimos que usa el poeta: troçir, passare, travessare y trrespasare. De todas ellas, passar en varias formas y funciones es la más usual, las demás no muestran la misma vitalidad.

\footnotetext{
5 Este uso no común ocurrió de forma parecida en León en el siglo X cuando un hombre se arrojó a los pies de su señor pidiendo clemencia y dijo: "O, Domine" en perfecto vocativo latino, cuando lo usual debió ser: "Dueño mie vida" (Menéndez Pidal 1979: 155). Lo que aquí aparece es la lengua del notario, no la de ese infeliz.
} 


\section{Ayuntar/juntar}

Ayuntar y juntar tienen, a lo largo del poema, una competencia singular, en la que juntar es usado en 10 versos en forma perifrástica, en uno como adjetivo y verbo conjugado en otro.

las gentes africanas fueron luego juntadas, $71 \mathrm{c}$ que fuesen en Muño todos con el juntados, 199b quando fueron juntados passaron allend mar, $72 \mathrm{~b}$ dexemos los juntados, byen nos debe menbrar. $604 \mathrm{~d}$ juntaron sus poderes quant ayna pudieron, $745 \mathrm{~b}$

Juntar es la forma menos usual sobre todo en las perífrasis verbales, y en 4 versos en la conformación de la rima:

las gentes africanas fueron luego juntadas, $71 \mathrm{c}$

Quando ovo rrey Rodrigo sus poderes juntados, $77 \mathrm{a}$

eue avye d'espannones los poderes juntados, 139d

que fuesen en muño todos con el juntados,199b)

con estructuras perifrásticas no adyacentes cuyo uso, como en los casos anteriores, obedece a la necesidad de conservar y/o iniciar la rima de la estrofa.

Por otro lado, el verso 199b, Marden (1904) lo incluye en la lista de los 143 versos mal medidos del poema, metro que hubiera resultado mejor si en lugar de juntados, el poeta hubiera usado ayuntados, pero no lo hace para evitar su repetición pues ha echado mano de la palabra 9 versos antes.

Ayuntar, por su parte, ofrece una muestra de 6 perífrasis verbales, una forma adjetiva y 7 como verbo conjugado:

e que eran ayuntados todos los del Reynado, $564 \mathrm{c}$

Era la corte todo en uno ayuntada, 57a

Formas perifrásticas éstas que siguen el patrón de uso de las anteriormente comentadas, ya que cuando se encuentran en el interior del verso guardan su estructura adyacente:

e que eran ayuntados todos los del Reynado, $564 \mathrm{c}$

pero cuando forman parte de la rima no lo son:

Era la corte todo en vna ayuntada, 57a

$\mathrm{Al}$ contrario del escaso uso de juntar en forma conjugada, el poeta prefiere usar ayuntar para expresar las acciones de los personajes en pasado y 
presente, al tiempo que lo reduce en las perífrasis en contraste con el que hace del otro verbo.

Pero ya en forma perifrástica, conjugada o como adjetivo, ayuntar $\mathrm{y}$ juntar compiten en el poema en el que aparece ayuntamiento con el significado de "coito': "de varon non qusyeron ningun ayuntamiento," $11 \mathrm{~b}$, y de casamiento: "todos tenían que era muy buen ayuntamiento," $581 \mathrm{~b}$ e inclina un poco la balanza hacia el mayor uso de ayuntar.

\section{Vençido/arrancado/rrancado ${ }^{6}$}

Otro par de sinónimos es vençido y rrancado o arrancado cuya aparición en el poema revela una competencia muy pareja.

Vençido, como participio, infinitivo aparece en 4 perífrasis verbales no adyacentes y estructurando rima:

Sabiendo commo eran sus poderes vençidos, $265 \mathrm{~b}$

O bien como infinitivo en un verso en el que se fuerza el orden auxiliar + infinitivo ${ }^{7}$ :

Vençer lo has en canpo deste terçero dia. $426 \mathrm{~d}$

Para lograr el metro o incluso obtener la rima:

Consejo les a todos de qual guisa fyziessen

sy el dia primero vençer no lo podiessen, $462 \mathrm{a}, \mathrm{b}$

Hay, asimismo, 5 perífrasis verbales más de estructura adyacente, tres de ellas en el interior del verso con participio:

el que suel ser vençido será el vençedor. 440d

$\mathrm{Y}$ en dos de ellas formando rima con infinitivo y participio:

dizie:"Feryt, caveros, que avedes vençido; $534 \mathrm{~b}$

nin moros nin cristianos non se podian vençer; $526 \mathrm{~b}$

6 Rancar procede de un germánico ranc (Zamora 1954: 24).

7 Este cambio de orden puede verse también en la Primera Crónica General: de sennores que somos fazernos emos siervos; et en vez de sacar Castiella de la premia en que esta doblargela emos, p. 392, cuyo copista o autor calca la sintaxis usada por el poeta (sobre todo la del verso d): de sennores que somos vassallos nos faremos/en vez que a Castiyella de su premia saquemos/la premia en que era doblar gela y emos (210 b, c, d). 
Finalmente, hay dos casos de verbo conjugado en futuro:

pero con tod el danno en canpo vençras. $405 \mathrm{~d}$

vençremos, non lo dubdes, a este bravo león, 414 b

Aparecen, en el poema, 5 perífrasis verbales no adyacentes con rrancado o arrancado, y todas ellas así se estructuran con objeto de conseguir la rima:

fueron de la primera los moros arrancados, $79 \mathrm{c}$

que avyan la los moros en el canpo rrancados; $81 \mathrm{~b}$

Con el mismo objetivo, se encuentran 3 perífrasis verbales adyacentes:

Sy Dios aquesta lid me dexa arrancar, 246a

que por el su consejo Almozor fue rrancado $429 \mathrm{c}$

Agreguemos a esta observación que rrancar o arrancar no aparecen conjugados en todo el poema. Esto puede indicar que el uso del verbo ha ido perdiendo vitalidad, y su número de apariciones (9) es una prueba de que está sucumbiendo frente a vençer.

\section{Toller/quitar}

Toller $^{8}$ aparece 7 veces en el poema, 5 como verbo conjugado con el significado de 'apartar, quitar':

que tuelle a las duennas verguença e pavor, $629 \mathrm{~b}$

ca tollo le don Cristo el su fuerte poder, $477 \mathrm{c}$

Y con el de 'mover algo de su sitio':

quand vyo que por y le tollio la entrrada, 135b

En la única perífrasis verbal que aparece tiene el significado de 'inutilizar o privar de su fuerza':

Tu que assy podiste a las yerbas toller, 111a

Construcción similar aunque con distinto significado a:

non podien las de Tarzo los ojos dellos toller, (Libro de Apolonio,106c)

8 Toller equivale a 'quitar, apartar, arrebatar' (Zamora 1954: 34). 
Esta misma forma de infinitivo aparece en función sustantiva:

ca el es poderoso de dar e de toller, $478 \mathrm{c}$

Por su parte, quitar solo es usado en 2 ocasiones en forma de verbo conjugado:

ca quito muy grand tierra al moro Almozor. 167d

Toller fue una forma muy usual, y su aparición en el poema corrobora esta condición que aparece en Berceo:

Tolgamos la corteza, al meollo entremos, (Milagros, 16c).

Y también en la Disputa del cuerpo e del anima:

Que aquestos gusanos non puedo toller

Aunque no llegó hasta nosotros esta forma, pero sí en la de tullirse 'inutilizarse' (Zamora 1954: 34).

2. Variación

Essas oras/estonçes

Hay tres formas que son las que tienen mayor uso en el poema:

Essas oras en 6 versos:

fueran se los paganos esas oras trornados, $81 \mathrm{c}$

Volvieron esas oras vn torneo pesado, 83a

Del buen rrey esas oras non sopieron mandado, $83 \mathrm{~d}$

Diera Dios esas oras grrand poder al pecado, 101a

Vençieron esas oras a frrançeses refez, 143c

Qui a Gustio Gonçalez esas oras matara, 536a

Estonçes en 4:

Estonçes fueron todos desto muy espantados: 255a

muchos fueron los otros que estonçes y morieron, $372 \mathrm{c}$

fizyera los el conde estonçes cavalleros, $450 \mathrm{~b}$

Fyzieron muy grand duelo estonçes los de Castyella, 600a

Essora también con cuatro:

cojieron se con todo essora los cruzados, 79d

fynco toda la tierra essora $\sin$ señor, $159 \mathrm{~d}$ 
sy essora toranarn fueran byen venturados $136 \mathrm{~d}$

Rrespondio a la duenna essora la infante, 626a

Además, aparecen otras:

Aquestas oras:

Dixo aquestas oras el conde don Yllian, 44a

Fueron aquestas oras fuerte miente esforçadas 493b

Estonçe:

Estonçe era Castyella vn pequenno rryncon, 170a

Era estonçe Espanna toda d'una creencia, 37a

Lo que estonçe perdiestes cobrar non lo podedes, $68 \mathrm{~d}$

Estonz:

estos viçios estonz heran dolores. $4 \mathrm{~d}$

de los que sanos eran estonz fueron vacios. 269d

estonz dixo: "Caveros, afán a en pobreza." $513 \mathrm{~d}$

\section{Entonz:}

Dixo entonz el conde... 256c

Por un lado, esta situación permite ver que no hay todavía en el dialecto castellano una norma lingüística dominante, pues en él conviven varias formas que intentan afirmar su uso: estonçes frente a estonçe, estonz y entonz, essas oras frente a aquestas oras, pero por el otro manifiestan un uso forzado al tratar de conseguir la rima y la métrica del verso y no tanto por una falta de norma.

Es decir, si intercambiamos algunas de estas voces por otras con las que están en competencia, la medida de ambos versos no resulta de 14 sílabas.

Esta misma situación de convivencia competitiva se da en formas como enemigo que aparece en 5 versos y nemigo que lo hace en solo uno, rribar y arribar con un caso cada uno, todavía y todavias en igual manera y desafiar que es usado en 3 versos y desfyar que está en 6.

La razón de uso de nemigo (66d) y rribar (133d) es la métrica del verso, situación que se ve claramente en:

mas valen çient caveros todos d'un cuer yguales, 302c

en donde coraçon no podría estar porque el verso resultaría de 16 sílabas, no así cuer porque es monosílabo. Lo mismo sucede con quand que sustituye 
al bisílabo quando en varios versos para que dé la medida exacta que exige la cuaderna vía:

quand fueron soterrados su camino tomaron. $563 \mathrm{~d}$

Lo mismo sucede con $c a$ cuando reemplaza al bisílabo porque en más de 40 versos, aunque éste aparezca en 5:

por que es toda Espanna en el nuestro poder, 59c $c a$ non as contra quien poner otros fronteros. $52 \mathrm{~d}$

Rima y métrica son pues, dos recursos literarios de los que el autor del poema echa mano, y muestra, en esta tarea, varios sinónimos y variantes de gran uso en la época pero supeditándolos, como hemos visto, a los patrones de la cuaderna vía que lo obligan, incluso, a formar plurales anómalos (ver nota 9) en su búsqueda de rima:

Avye de buroveses otrrossy trevinnanos caveros bien ligeros, de coraçon loçanos, 455a, b los del conde eran pocos mas buenos conbatyentes todos eran yguales d'un coraçon ardientes. 250c, d

Y en la búsqueda de la medida exacta del verso y rima consonante:

por çient lanças se vençen las fazienda canpales

mas valen mil caveros todos de un cuer yguales $^{9}, 302 \mathrm{~b}, \mathrm{c}$

La siguiente estrofa evidencia que este plural anómalo está mal usado pues no hay rima consonante en el verso c (loçanos), aunque sí asonancia propia de la juglaría castellana que la utilizó hasta el siglo XV.

Assaz eran navarros caveros esforçados, que en cualquier lugar serian buenos prouados, omnes son de grand cuenta, de coraçon loçanos, mas eran en el conde todos desuenturados. $751 \mathrm{a}, \mathrm{b}, \mathrm{c}, \mathrm{d}$.

9 Puede tratarse, como en el caso de pechos $<$ pectus de la conservación de s etimológica: yguales<aequalis; sin embargo, hay usos de la voz en singular que anularían esta afirmación: "e del Spiritu Santo que ygual dellos posa," 1c y "Estaba la fazienda toda en ygual estado," $40 \mathrm{a}$, versos que afianzarían que este uso anómalo del plural se deba a la obtención de la medida y rima de ellos. Por otro lado, si la puntuación fuera otra de los versos 455b, 302c y 250d, es decir, si se anotara una coma antes de loçanos, yguales y ardientes estos plurales no resultarían extraños, pues se estarían refiriendo a caveros, conbatyentes y caveros respectivamente, y, de hecho, a ellos se refieren y no a coraçon o a cuer, pero son puestos al final del verso motivados por la rima y no inmediatamente después de los sustantivos calificados. Los plurales anómalos son, pues, un espejismo. 
El verso b de la siguiente estrofa puede parecer un uso anómalo del plural:

Cuando fueron al puerto los franceses llegados,

Rrendieron a Dios grraçias que los avya guiados, 136a, b.

Pero se trata de una construcción de haber + participio transitivo concordado, es decir, que concuerdan participio y objeto directo ${ }^{10}$ :

bien semeja que Dios nos a desanparados, $522 \mathrm{c}^{11}$

Igual que sucede en:

Al rey Yuçef tres colpes le ovo dados, (Cid, 1725)

Y en estos fragmentos de la Primera Crónica General: vos veredes quel acallonare los tuertos que nos ha fechos en manera que..., p. 397... que si quiere enmendarle los tuertos que avie fechos a castellanos..., p. 396.

Pero distinto a:

Al Rey Fariz ijj colpes le avie dado, (Cid, 760)

En donde no hay sintaxis concordante que en el siglo XIII arroja un 68\% en el corpus que analiza Romani (2006: 284), en el siglo XIV se reduce al $11 \%$ y en el XV desaparece.

\section{LA SINTAXIS CONCORDANTE}

En el poema, la sintaxis concordante alcanza el 79\% (34/43) de las formas documentadas de haber + participio, en tanto que la no concordante llega al 21\% (9/43). De la primera, la forma ovo + participio es la más usual, le sigue avya + participio; de la segunda resultó avya + participio y avian +

10 Estos casos solamente resultan claros cuando el objeto directo es masculino plural, -o, o bien femenino singular y plural, -a, -as, pues en los masculinos singulares es imposible saber si se opera o no una sintaxis concordante, la cual constituye un residuo morfológico de la función adjetival que tenía el participio: Con los caualleros que el Cid les avie dados (Cid, 1051) y que alterna libremente con la sintaxis no concordante en el español medieval (Véase Romani 2006 y Company 1983).

11 Este verso lo reconstruye Marden (1904) con base en la Primera Crónica General en la que puede leerse: "et bien semeia que Dios nos a desanparados; et fizieramos meior si nos ovieramos tornados"..., p. 394. 
participio las más utilizadas y luego $a s+$ participio y $a+$ participio, que son formas propias de una narración en pretérito.

De las 43 apariciones de haber + participio, 35 forman rima y de éstas 26 están estructuradas en sintaxis concordante ${ }^{12}$. Es en la estrofa 8 en donde aparece por primera vez este tipo de sintaxis y estructura rima consonante en los versos $a$ y $b$, y la no concordante en el verso $d$ con rima asonantada que es de las pocas de esta naturaleza pues todas las demás hacen consonancia, rima que, dicho sea, no es muy variada pues se circunscribe a 5 formas: -ados (10 casos), -ada (11) $)^{13}$, -idos (2) y -adas e -ida con un caso cada una. Finalmente, 10 son los casos concordados que abren estrofa y guían rima (ver nota 11). Las 16 formas restantes se distribuyen, sobre todo, en los versos b ( 8 casos) y las que no hacen rima en el a (4 casos). El siguiente cuadro muestra la relación entre los dos tipos de sintaxis y la adyacencia del auxiliar y del participio en versos rimados y sin rima.

\section{Cuadro 1}

Sintaxis concordante y o concordante, rima y adyacencia haber + participio

\begin{tabular}{|l|l|l|}
\hline Tipo de sintaxis y adyacencia & Casos & Versos \\
\hline Sintaxis concordante adyacente con rima & 6 casos & $\begin{array}{l}10 \mathrm{~b}, 136 \mathrm{~b}, 255 \mathrm{c}, 323 \mathrm{a}, \\
353 \mathrm{a}, 357 \mathrm{~d}\end{array}$ \\
\hline Sintaxis no concordante adyacente con rima & 4 casos & $48 \mathrm{~d}, 272 \mathrm{c}, 278 \mathrm{a}, 684 \mathrm{c}$ \\
\hline Sintaxis concordante no adyacente con rima & 20 casos & $\begin{array}{l}8 \mathrm{a}, 8 \mathrm{~b}, 77 \mathrm{a}, 81 \mathrm{~b}, 123 \mathrm{~b}, \\
139 \mathrm{~d}, 265 \mathrm{~d}, 280 \mathrm{c}, 224 \mathrm{a}, \\
259 \mathrm{a}, 291 \mathrm{a}, 291 \mathrm{~b}, 308 \mathrm{a}, \\
463 \mathrm{a}, 505 \mathrm{~b}, 673 \mathrm{~d}, 685 \mathrm{a}, \\
719 \mathrm{c}, 724 \mathrm{~b}, 728 \mathrm{c}\end{array}$ \\
& & $\begin{array}{l}8 \mathrm{~d}, 42 \mathrm{c}, 198 \mathrm{a}, 293 \mathrm{c}, \\
717 \mathrm{a}\end{array}$ \\
\hline Sintaxis no concordante no adyacente con & 5 casos \\
rima & & $\begin{array}{l}55 \mathrm{a}, 345 \mathrm{a}, 380 \mathrm{~d}, 723 \mathrm{a}, \\
724 \mathrm{c}\end{array}$ \\
\hline Sintaxis concordante adyacente sin rima & 5 casos & \\
\hline Sintaxis no concordante adyacente sin rima & 0 casos & $179 \mathrm{c}, 280 \mathrm{~b}, 446 \mathrm{a}$ \\
\hline Sintaxis concordante no adyacente sin rima & 3 casos & \\
\hline Sintaxis no concordante no adyacente sin rima & 0 casos & \\
\hline
\end{tabular}

12 Son los versos 8a, 8b, 10b, 77a, 81b, 123b, 136b, 139d, 179c, 224a, 232a, 255c, 259a, 265d, 280c, 291a, 308a, 353a, 357d, 463a, 505b, 673d, 685a, 719c, 724b y 728c.

13 Con esta forma se recurre varias veces a las frases rrazon acabada u oraçion acabada. 
De los 33 versos rimados hay 10 en que el auxiliar y el participio están adyacentes y el resto (23) no lo está. Por otro lado, son 5 de los no rimados los que muestran adyacencia y 3 no la ostentan. La adyacencia del auxiliar y el participio domina el español desde los primeros siglos (Romani 2006: 288-289), pero en este poema la situación es al revés. Esto solo puede ser explicado atendiendo a cuestiones de ciertos rasgos estilísticos asociados a estas alternancias aparentemente libres (Berta 2009: 675). Veamos la estrofa 42:

El conde don Yllan, byen avedes oydo, commo ovo por las paryas a Marruecos troçido; ovo en est comedio tal cosa conteçido, por que ovo el rreyno ser todo destruido.

En el primer verso hay adyacencia y el participio pone la rima. En el verso $b$ hay sinalefa en commo ovo que pudo haber estado en otro sitio: por las paryas a Marruecos commo ovo troçido, que no variaría el metro y procuraría adyacencia aunque no es tan eufónico; en el $c$ el orden pudo ser otro: en est comedio tal cosa ovo conteçido, pero el poeta sigue el modelo del verso anterior separando el auxiliar del participio y respetando el hemistiquio, y lo mismo hace en el $d$.

Veamos ahora el caso de la estrofa 8:

Desque ovo Mafomat a todos prredicados, avyan las gentes los cueres demudados,

e la muerte de Cristo avian la olvidado.

El verso $a$ puede tener otro orden sin alterar su metro: Desque Mafomat a todos ovo prredicados, el $b$ tiene problemas en la medida, pero aun así puede unir el auxiliar y el participio: las gentes los cueres avyan demudados, lo mismo puede suceder en el $d$. Sin embargo, el poeta ya tiene un modelo que le ha resultado bueno para lograr la rima: haber + el sujeto o el objeto directo + el participio rimado en consonancia o asonancia, sobre todo en -ada y-ados (ver arriba).

En el verso $d$, el poeta muestra una concordancia no ambigua ${ }^{14} \mathrm{y}$ de ese modo no consigue la rima consonante. Es decir, la sintaxis concordante de los versos $a$ y $b$ no puede ser repetida en el $d$ porque muerte es femenino

14 La concordancia no ambigua, que ocurre entre el participio terminado en -o y un objeto directo con rasgos no masculino no singular, representa el $41.3 \%$ en los 104 casos de haber 
singular, aunque pudo obtenerla (no la rima sino la sintaxis) usando olvidada, pero no lo hace porque la falta de rima sería muy visible, y prefiere el masculino singular cuyo participio, a pesar de no concordar con el objeto directo (muerte), produce asonancia. Y esto es lo más importante pues su consecución está por encima del tipo de concordancia usada o de la adyacencia o no del auxiliar y el participio.

Ahora bien, las formas concordadas son más frecuentes entre las estrofas 224 y 291 (9 casos), 8 casos formando rima y uno en el interior del verso (280b) y apiñándose en pares en las estrofas 280 y 291. La menor presencia está en la parte que va de la estrofa 500 a la 599 con un solo caso (505), estrofa que, como se ha visto, tiene una rima anómala en el verso $a$ lo que hace suponer que, tal vez, no pertenezca a ella.

Por otro lado, la no adyacencia del auxiliar y del participio es mayor en las formas concordadas que en las no concordadas, y el orden inverso, es decir, participio + auxiliar no aparece en aquéllas pero sí en éstas ( 1 caso). El cuadro siguiente registra el número de casos de este análisis:

\section{Cuadro 2}

Haber + participio

Sintaxis concordante y no concordante, rima, adyacencia y orden auxiliar + participio

\begin{tabular}{|l|c|c|c|}
\hline & $\begin{array}{c}\text { Estrofas } \\
1-376\end{array}$ & $\begin{array}{c}\text { Estrofas } \\
377-752\end{array}$ & Casos \\
\hline Sintaxis concordante & 23 & 11 & 34 \\
\hline Sintaxis no concordante & 7 & 2 & 9 \\
\hline Sintaxis concordante adyacente & 8 & 3 & 11 \\
\hline Sintaxis concordante no adyacente & 15 & 8 & 23 \\
\hline Sintaxis no concordante adyacente & 3 & 1 & 4 \\
\hline Sintaxis no concordante no adyacente & 4 & 1 & 5 \\
\hline Sintaxis concordante con rima & 19 & 7 & 26 \\
\hline Sintaxis concordante sin rima & 4 & 4 & 8 \\
\hline Sintaxis no concordante con rima & 7 & 2 & 9 \\
\hline Sintaxis no concordante sin rima & 0 & 0 & 0 \\
\hline Sintaxis concordante orden participio + haber & 0 & 0 & 0 \\
\hline Sintaxis no concordante orden participio + haber & 0 & 1 & 1 \\
\hline
\end{tabular}

+ participio estudiados, es decir, es menor que la ambigua que, según Romani (2006: 286) se usó más en el siglo XII y fue disminuyendo en los siglos posteriores. 
Como se puede apreciar, en las primeras 376 estrofas, tanto la sintaxis concordante como la no concordante tienen más del doble de casos que en las siguientes 376. ¿Por qué este comportamiento sintáctico? Al contener más sintaxis concordante que no concordante, el poema queda inscrito en el siglo XIII en que la primera dominaba sobre la segunda (Company 1983: 246). Sin embargo, llama la atención que los dos tipos de sintaxis estén más usados entre la estrofa 1 y la 376. ¿Acaso hay un lapso que separa la hechura de estas dos secciones del texto o estamos ante un poema en el que intervino más de una mano y no solo la de los dos copistas como sugiere Marden (1904)? Por otro lado, la no adyacencia del auxiliar y del participio lo caracteriza también como del siglo XIII en el que el índice de interpolación de elementos es relativamente elevado ${ }^{15}$ (Company 1983: 251-252), aunque esto último puede tratarse de una cuestión puramente estilística y más tratándose de un texto literario (ver arriba).

En la primera parte se puede hallar el mayor uso de los sinónimos analizados (salvo vençer), el de essas oras y essora y la mayor variación de estonçes.

La sintaxis concordante, como se ha visto, caracteriza al poema como un texto propio del siglo XIII pues esta forma es más abundante que la no concordante:

Desque que ovo Mafomat a todos prredicados, $8 \mathrm{a}$ avyan las gentes los cueres demudados, $8 \mathrm{~b}$ con señor de Cantabria ovyeron la casada, 123b rrendieron a Dios grraçias que los avya guiados, $136 \mathrm{~b}$

Sin embargo, este tipo de sintaxis no aparece en otros tantos versos como los siguientes:

cojyeron sus averes que Dios les avya dado, 272c

Avyan a toda Canpos corrydo e rrobado, $717 \mathrm{a}$

quando ovo el rrouo a sus casas tornada, $724 \mathrm{~b}^{16}$

15 La no adyacencia en todas las formas compuestas del poema alcanzan el 59\%, y el mayor número de casos se halla en lo que hemos considerado como la primera parte (estrofas 1-376).

${ }_{16}$ Esta forma de manifestar el perfectum también puede leerse en la Primera Crónica General: ...tuertos que nos a fechos,... si nos ovieramos tornados...,... Dios nos a desanparados,...p. 394,...los tuertos que nos avie fechos a castellanos..., p. 396, que es uno de los aspectos centrales, entre otros, de la evolución del verbo latino al verbo romance. 
En estos versos, los participios debieron ser dados, corrida e rrobada y tornado para que concuerden sintácticamente con averes, toda Canpos y rrovo $^{17}$, respectivamente, pero las formas usadas se deben a la demanda de la rima que obliga al poeta a usar un singular masculino del participio (272c y $717 a)^{18}$ y otro en singular femenino $(724 b)^{19}$, uso que no aparece en $77 a$ aunque juntados (que tiene concordancia con poderes) no rime con el verso $\mathrm{d}$ de la estrofa: ca fue de los profetas esto profetizado., aunque sí con el b y el c.

La información lingüística que nos brinda el poema hace pensar en un uso considerable de las formas verbales compuestas, pues éstas aparecen en poco más del $27 \%$ de los versos que conforman las primeras 200 estrofas del texto de diversas maneras: 1. El participio concuerda con el objeto directo en verbos auxiliados por haber (ver arriba), y con el sujeto en verbos auxiliados por ser: ya eran en Tolosa con su señor llegados, 380b, 2. Orden sintagmático auxiliar más participio no fijo: establecidos fueron lugares señalados, $31 \mathrm{c}$, 3. Intercalación de otros elementos entre el auxiliar y el participio: e eran todas las gentes en la fe arraigadas, $38 \mathrm{~d}$, y cuyo uso en la lengua oral ha sido difícil de determinar ya que muchos de los estudios que se han realizado sobre esta modalidad están basados casi exclusivamente en textos literarios (Rodríguez 2003:294 nota 15), y ello sesga la visión que nos proporciona la gramática histórica sobre las formas verbales compuestas en el romance medieval castellano.

Finalmente, si la consecución de la rima -sobre todo- y el metro como elementos literarios necesarios supedita el uso de sinónimos y variantes en el poema, esto no puede afirmarse como única condición, pues si el poeta eligió troçido o pasado, juntar o ayuntar, si usó El conde, cavalleros, las pazes a firmadas en lugar de El conde, cavalleros, las pazes a firmado, o bien cueres en vez de coraçones o estonçe en vez de estonz, es porque esas formas eran muy conocidas y usuales en la lengua hablada, porque eran entendidas perfectamente estas voces y esta sintaxis por el lector y el auditorio, y ello indica inestabilidad del dialecto castellano, el propio sistema permite su uso polimórfico y no solo la rima y el metro de la cuaderna vía son los responsables de este uso aún no regulado.

17 Menéndez Pidal (1905: 256) sugirió sustituir rrovo por ganançia para que concuerde con tornada, y después (1951: 148 y 180) una lectura con prea que aparece en los versos $721 \mathrm{a}, 723 \mathrm{~b}$ y $741 \mathrm{~b}$.

18 Tal vez usados no tanto para lograr la rima sino impuestos por una norma sintáctica que cada día se instalaba más en el naciente castellano, la de la sintaxis no concordante.

19 La explicación del uso de tornada solo puede hacerse atendiendo a la necesidad de rima, o bien se trata de un error de transcripción paleográfica, si no se atiende la sugerencia de Menéndez Pidal (nota 17). 


\section{CONCLUSIONES}

El Poema de Fernán González, obra de clerecía con tema de juglaría hecho por un poeta culto arlantino, convoca a varias voces en sus historias en las que prevalece las del narrador omnisciente que todo lo sabe, que es ubicuo y que cuenta, a su modo, las contiendas de este conde castellano y su fonsado que lucha pos sacar de la premia a una Castilla herida por los moros y maltratada por navarros y leoneses.

Esta voz, que está creando arte literario, tiene una manera singular de exponerlo. Y en esta tarea, nos ofrece elementos de la lengua del siglo XIII que hemos analizado mediante pares de conceptos sinónimos y ciertas variantes fonéticas y morfológicas, sinónimos que, si el hablante es culto, suelen ser más, y variantes que suelen ser menos a medida que el sistema empieza a ser regido por una costumbre de uso que la nutre y renueva.

El estilo propio de un juglar aparece en contadas ocasiones en el texto, y aunque al final de su canto, este cantador no pida vino ni soldada, atrae la atención de su público para que oiga los fechos d'armas de los caballeros de coraçones loçanos dirigidos por las acciones y los discursos del conde:

byen creo que lo oyestes alguna vez contar, $118 \mathrm{~d}$

oyredes lo que fyzo al conde tolosano, $373 \mathrm{~b}$

Y al presentar estas series de hechos heroicos se arropa con todos los recursos que la lengua castellana le brinda en este ensayo que emprende sometiéndose a los principios fundamentales de la cuaderna vía, situación muy distinta a la del juglar que se movía entre la imperfección métrica y la asonancia. En su trabajo, el monje perseguirá la perfección métrica y la consonancia, y aunque no lo logra totalmente, en esa persecución somete a las reglas de estos dos aspectos a los sinónimos y variantes de las voces de las que echa mano.

Practica, asimismo, la libre elección de las voces que ha de usar: repite algunas que hacen rima en la misma estrofa:

El señor que creó la tierra e la mar,

$\mathrm{El}$, que es buen maestro me debe demostrar

de las cosas pasadas que yo pueda contar:

commo cobro la tierra toda de mar a mar. (2)

Encabalga perífrasis verbales de modo abigarrado:

--Sennor, sy tu quisieres mi consejo tomar, igrrado a Dios del çielo qie te fyzo rreynar!

Nin moro nin cristiano non te pued contrrallar, ¿Las armas que las quieres? Pues non as pelear. (50) 
Rompe el orden de algunas estructuras perifrásticas adyacentes

fare a don Rrodrygo sus caveros juntar

fer les e todas armas en el fuego quemar $(45 \mathrm{~b}, \mathrm{c})$

Conjuga verbos actualizando las acciones:

lavole e vestyol' d'un xamete preçiado, echol'en vn escanno sotyl mientre labrado (374b, c)

Adjetiva:

Tolosanos mesquinos, llorando su malfado sus caras afiladas, pueblo mal deserrado, llegaron a Tolosa, cabeça del condado, fue commo de primero elllanto renovado. (379)

Deja acciones en suspenso:

Dexemos al conde en grand pryessa estar (515a)

Retoma otras:

Tornemos en el conde dol' avemos dexado, $\left(605^{\mathrm{a}}\right)$

Propone rimas graves:

San Juan Evangelista ante muchos varones, yazian ante el muertos de yerbas dos ladrones, veuio el muy grand vaso d'essos mismos ponçones, mayor mal nol' fizieron que sy comies pinnones. (110)

Y también rimas agudas:

Sennor, tu que libreste a Davyt del león, matest al Filisteo, vn soberbio varon, quitest a los jodios del rrey de Baiblon, saqua nos e libra nos de tan cruel presyon. (107)

Pero en todo su discurso somete a los cánones de la cuaderna vía al aparato lingüístico y yerra en algunas rimas:

Todos los mis vassallos que aquí son finados, serian por su señor esta dia vengados, todo sen paraíso conmigo ayuntados, faria muy grand honrra el cond a sus vasallos. (549)

Y en el metro de algunos versos (ver Marden 1904: lii). 
Menéndez Pidal (1975: 198) habla de la extraordinaria irregularidad métrica del poema y de la fuerte atracción que ejercieron en el poeta la ametría de las gestas y los asuntos heroicos que ya desde antiguo dominaban en Castilla ${ }^{20}$.

Pero ésa no es solamente la característica del poema sino también lo son su entrada tan parecida a la de la Vida de Santo Domingo de Silos de Berceo y el paseo por la geografía castellana que incluye, desde luego, el camino francés tan importante en el desarrollo del castellano debido a los vaivenes de los peregrinos que dejaron huella en su conformación.

Sin embargo, lo más singular, me parece, es la lengua que utiliza el poeta y la manera de presentarla al lector y al auditorio que, tal vez, no supiera quién había sido Fernán González, pero que se sintió atraído por la historia y terminó comparándolo con el Cid de las gestas heroicas, aunque el poema sea inferior literariamente porque no tiene metáfora alguna ni figuras literarias bien desarrolladas.

El poema es una narración de hechos, de microhistorias que adereza el poeta con rimas engarzadas en acciones bélicas y discursos amenos del conde quien incita a sus vasallos a no perderse en viçios y aprovechar las horas porque los hombres de buenos fechos siempre serán recordados.

Para el concepto 'moverse de un sitio a otro' nuestro poeta usa 4 verbos: troçir (en forma de perífrasis no adyacente), passar (en perífrasis no adyacente, adyacente, como infinitivo y participio y en forma simple con los significados de 'padecer', 'morir', 'de tiempo' y el ya mencionado), trravessar y trrespassar en forma perifrástica y simple el primero, y solo simple el segundo. Esto deja ver que passar es el preferido pues tiene varios significados y formas con las que elabora los versos los rima y les da el metro exacto.

Troçir tiene documentación en el CORDE desde 1140 en el Poema del Cid y hasta 1236 en la Vida de Santo Domingo de Silos de Berceo, y su exigua aparición en el poema hace pensar que su uso se perdió antes de iniciar el siglo XIV. Y no es el primer verbo al que recurre el poeta para indicar movimiento de algo animado (42b) y pocas estrofas más adelante usa $\operatorname{travessar}^{21}$ (46b) y passar $^{22}$ (47a), mostrando cierto cuidado al elaborar el discurso y no repetir la voz aunque no puede conseguirlo totalmente ya

20 Con seguridad, el poeta conoció la historia del cerco de Zamora, la de los infantes de Salas, la de la mora Zaida, la del Cid, la novela de la hija del conde don Julián y otras que andaban por plazas y calles de Castilla durante el siglo XIII.

21 Documentado en el CORDE desde 1240 en el Libro de Alexandre.

22 Ya usado antes en 4a, 18a y 25a con los significados de 'padecer', 'trasladarse' y 'morir', respectivamente. 
que vuelve a usar passar $^{23}$ con el mismo significado en 48a, y más adelante, en 71b, 72a y 72b, vuelve a cometer el mismo yerro.

Algo similar ocurre con juntar en 71b, 72a, 72b y 77a, al igual que con ayuntar ${ }^{24}$ en $76 \mathrm{~d}$ y $78 \mathrm{c}$ ya usado desde 31 a y $57 \mathrm{a}$, y todo ello guarda cierto balance con juntar en los versos señalados en los que lo mejor hubiera sido ponerlos alternados para evidenciar así un discurso más pulido y cuidado.

Con vençido y rrancado no hay alternancia de uso, pues por separado ambos adjetivos o participios cumplen su función con cierta cercanía: rrancado (versos 79c, 81b, 85a, 243b, 246a) vençido (versos 265b, 270a) que vuelven a ser usados 40 y 80 estrofas después, respectivamente.

Toller tiene una cronología de uso bien ordenada, salvo en las estrofas 477 y 478 en que aparece repetido cercanamente y en formas de sustantivo y de verbo conjugado, en tanto que quitar, como verbo conjugado, aparece por primera vez en la estrofa 107 y luego 60 estrofas después.

En cuanto a las formas que presentan variantes, es estonçes la que en el CORDE tiene más frecuencia de uso (3828 casos desde el año 1218 al de 1517) y la que menos es essas oras con solo 6 desde 1250, 5 en nuestro poema y 1 en otro texto de 1400, estonçe tiene 1538 apariciones, estonz 163 y entonz solamente 33 .

\section{REFERENCIAS BIBLIOGRÁFICAS}

BERTA, T. 2009. Frecuencia de fenómenos sintácticos arcaicos en construcciones de tipo haber + participio. Separata de las Actas del VII Congreso Internacional de Historia de la lengua española, pp. 673-681. E. Moreno (ed). Madrid: Meubook.

BouterveK, F. 1829. Historia de la literatura española, J. Gómez y N. Higalde (trads.). Madrid: Imprenta de Eusebio Aguado.

Company, C. 1983: Sintaxis y valores de los tiempos compuestos en el español medieval. Nueva Revista de Filología Hispánica, t. XXXII, núm 2: 235-257.

Marden. 1904. Poema de Fernán González. Madrid: Librería de Murillo, Baltimore, The Johns Hopkins Press.

Menéndez Pidal, R. 1975. Poesía juglaresca y juglares. Madrid: Espasa Calpe. 1979. El español en sus primeros tiempos. Madrid: Espasa Calpe.

1904. Reseña de Marden. En Archiv fur das Studium der neueren Sprachen [und Literaturen] 114, (1905): 243-257.

23 Aparece en el CORDE en 1250 en un texto del Fuero general de Navarra.

24 La primera documentación en el CORDE es de 1196 en la forma ayuntado en un texto del Fuero de Soria y en 1256 como ayuntar en Picatrix de Alfonso X. 
1951. Reliquias de la poesía épica española acompañadas de Epopeya y Romancero.

I. Madrid: Cátedra-Seminario Menéndez Pidal, Gredos, 1980.

1955. Alfonso X Primera crónica general de España. Madrid: Gredos.

Real Academia Española. Banco de datos (CORDE) [en línea]. Corpus diacrónico del español. $<$ http://www.rae.es $>$ [01 de junio de 2016]

RODRíguez, J. 2003. Algunas reflexiones sobre el origen y formación de la perífrasis haber + participio en la lengua medieval. Res Diachronicae 2: 294-302.

Romani, P. 2006. Tiempos de formación romance I. Los tiempos compuestos. En Company C. (ed.). Sintaxis histórica de la lengua española. Primera parte: la frase verbal, vol. I, pp. 243-345. México: UNAM/FCE.

Zamora Vicente, A. 1954. Poema de Fernán González. Madrid: Espasa Calpe. 